\title{
บUisuersily
}

\section{On the processing of alternatives, exhaustification and covert negation: the case of "mai"}

Romoli, J. (Accepted/In press). On the processing of alternatives, exhaustification and covert negation: the case of "mai". In A. Falaus (Ed.), Alternatives in semantics (pp. 209-237). Palgrave Macmillan.

Link to publication record in Ulster University Research Portal

\section{Published in:}

Alternatives in semantics

Publication Status:

Accepted/In press: 05/05/2011

\section{Document Version \\ Author Accepted version}

\section{General rights}

Copyright for the publications made accessible via Ulster University's Research Portal is retained by the author(s) and / or other copyright owners and it is a condition of accessing these publications that users recognise and abide by the legal requirements associated with these rights.

\section{Take down policy}

The Research Portal is Ulster University's institutional repository that provides access to Ulster's research outputs. Every effort has been made to ensure that content in the Research Portal does not infringe any person's rights, or applicable UK laws. If you discover content in the Research Portal that you believe breaches copyright or violates any law, please contact pure-support@ulster.ac.uk. 


\title{
On the processing of alternatives, exhaustification and covert negation: the case of mai
}

\author{
Daniele Panizza and Jacopo Romoli
}

\section{INTRODUCTION}

In this paper, we focus on the linguistic behavior and on-line processing of the Italian word $m a i .{ }^{1}$ We are interested in mai as it exhibits typical properties of Negative Polarity Items (NPIs) on the one hand and of Negative-words (N-words) on the other. mai exhibits sensitivity to the entailment patterns associated with the sentence in which it occurs, a feature that characterizes NPIs in general. Moreover, mai gives rise to different meanings depending on its position with respect to the verb, a characteristic of N-words. In this paper, we propose an alternative-based analysis of mai as an NPI with the additional capacity of introducing a covert negation in certain environments in pre-verbal position. The main goal of this project is to investigate, through the case study of mai, the on-line processing of the theoretical mechanisms that we argue are involved in its semantics, such as alternatives, exhaustification and insertion of covert negation. With this goal in mind, we make explicit hypotheses on how such mechanisms are 
connected to on-line processing, and we test these hypotheses using the event related potential (ERP) methodology. In the experiment we report below, we manipulated the presence of negation and the position of mai with respect to the verb, and we presented speakers of Italian with a set of sentences where only these two factors were varied, while their electroencephalography was recorded. The main result of the study is that the insertion of covert negation is a reanalysis triggered by the contradictory meanings arising from the exhaustification of mai with respect to its alternatives. For our purposes, the role of semantic alternatives is critical in two respects. On the theoretical side, we adopt an approach based on alternatives and exhaustification in order to predict the distribution of mai in pre-verbal versus post-verbal position. On the psycholinguistic side, we use these theoretical tools in order to account for the pattern of electrophysiological effects we found in our study and, as we discuss in the final section, have been found in other experiments on NPI violations.

In the remaining part of this introduction, we introduce the empirical properties of mai which are relevant for the present study. Then, we briefly discuss some of the theoretical tools employed in the literature for analyzing NPIs and N-words, which will be crucial for our analysis of mai.

\subsection{Mai}

\subsubsection{Similarities and Differences with NPIs}


In post-verbal position, mai exhibits the distributional restrictions of a regular NPI like ever and it is interpreted as such. ${ }^{1}$ A distinctive characteristic of NPIs is that their distribution is restricted to Downward Entailing (DE) environments (Ladusaw, 1979; see Chierchia, 2011, for discussion). For instance, in (1), ever is licensed in the scope of overt negation whereas in (2) it is embedded in the first argument of every. Both of these environments are DE. ${ }^{2}$

(1) John hasn't ever eaten broccoli.

(2) Every student who ever ate broccoli knows how tasty it is.

On the other hand, ever cannot occur in non-DE environments like simple positive sentences, (3), or in the second argument of every, as in (4).

(3) *John has ever eaten broccoli.

(4) *Every student who knows how tasty broccoli is has ever eaten it.

In the very same way, mai is ungrammatical in post-verbal position (5), unless it appears in the scope of DE operators as in (6) and (7).

(5) *Gianni ha mai mangiato i broccoli 
Gianni has ever eaten broccoli

(6) Gianni non ha mai mangiato i broccoli

Gianni has not ever eaten broccoli

(7) Ogni studente che abbia mai assaggiato i broccoli sa quanto sono gustosi Every student who has ever tasted broccoli, knows how tasty it is

In the examples above, mai has the same distribution and interpretation as ever, hence one might be tempted to analyze it in the very same way (i.e. as a regular NPI). However, in pre-verbal position, mai crucially differs from ever and other NPIs. In fact, in that position, unlike ever, it is grammatical even if not in a DE environment. In such cases, exemplified in (8) and (9), it is typically stressed and it acquires a negative interpretation (i.e. it is interpreted as never).

(8) Gianni mai ha mangiato i broccoli

Gianni has never eaten broccoli

(9) Mai avrei pensato che a Gianni piacessero i broccoli

I would never have thought that Gianni likes broccoli

\subsubsection{Similarities and Differences with $\mathrm{N}$-words}


In the preceding section, we saw that the behavior of mai in pre-verbal position differs from that of NPIs, rather it is similar to that of N-words in Italian. For instance, nessuno, which alternates between the meaning of no one and of anyone depending on its position, shows the same behavior: in post-verbal position, as in (10), it is licensed in the scope of negation and is interpreted as anyone; in pre-verbal position, as in (11), it acquires a negative interpretation and is interpreted as no one.

(10) Non ho visto nessuno mangiare i miei broccoli. I haven't seen anybody eating my broccoli

(11) Nessuno ha mangiato i miei broccoli No one has eaten my broccoli

In the examples above, mai and other n-words like nessuno exhibit the same distributional properties and the same interpretation pattern. However, just as we cannot simply classify mai as an NPI, we cannot classify it as an N-word either. There are two main differences that distinguish mai from (Italian) N-words. The first one regards the interpretation of mai in pre-verbal position: while N-words like nessuno are always interpreted negatively in this position (as no one), this is not the case for mai. To illustrate this difference, consider (12) and (13): in both cases the N-word nessuno appears in a DE environment and in both cases it is assigned a negative meaning (i.e. it is 
interpreted as no one and not as anyone).

(12) Se nessuno andasse a Cuba in vacanza, lo stato fallirebbe If no one went to Cuba on holiday, the nation would go bankrupt

(13) Ogni professore che nessuno vuole avere come relatore verrà licenziato. Every professor that nobody wants to have as advisor will be fired

On the other hand, mai in the same contexts, (14) and (15), is not assigned a negative meaning (i.e. never), but rather it is interpreted as ever.

(14) Se mai dovessi andare a Cuba, ci andrei da solo If I should ever go to Cuba, I will go there alone

(15) Ogni prigioniero che mai osi attraversare questo cancello sarà fucilato Every prisoner who will ever dare to go through this gate will be shot

The generalization seems to be that contrary to $\mathrm{N}$-words, in DE environments mai is always interpreted as ever, regardless of its position with respect to the verb. ${ }^{3}$

A second difference between mai and N-words regards their licensing environments in post-verbal position: while mai can occur in all DE environments, Nwords are more restricted, as they have to appear under the scope of overt negation or 
other negative operators (see Alonso-Ovalle and Guerzoni, 2004, for discussion). To illustrate, compare (16) with (17) below: while mai can occur in the restrictor of ogni (every) in post-verbal position with the interpretation of ever, $\mathrm{N}$-words like nessuno in the same structural position are not grammatical, unless we also introduce a negation as in (17).

(16) Ogni studente che abbia mai mangiato dei broccoli si ammalerà Every student who has ever eaten broccoli will get sick

(17) Ogni studente che *(non) ha mangiato nessun broccolo, si ammalerà Every student who has (not) eaten no broccoli will get sick

The same holds for the antecedent of conditionals: compare (18) to (19) below.

(18) Se Gianni mangerà mai dei broccoli, scoprirà quanto sono buoni If Gianni ever eats broccoli he'll find out how good it is

(19) Se Gianni *(non) mangerà nessun broccolo ne mangeremo di più noi If Gianni (not) eats none of the broccoli we will eat more of it

Summing up, while mai behaves like an NPI when it is in post-verbal position, it differs from NPIs when it occurs pre-verbally, in that it can also occur in non-DE 
environments by acquiring a negative meaning. Although this last property is shared with other N-words in Italian, mai differs from N-words because a) it is not always interpreted negatively in pre-verbal position, but only when not in a DE context and b) its distribution is less restricted than the one of $\mathrm{N}$-words in post-verbal position. Its behavior is, therefore, not captured by accounts of pure NPIs or N-words. In the following, we sketch an account of mai modeled on Chierchia's (2011) theory of NPIs, which, together with a mechanism for deriving the negative interpretation in pre-verbal non-DE contexts, can account for the data above. The gist of the proposal is that mai is an NPI with some additional properties. In the next section we present the ingredients of Chierchia's analysis of NPIs that are relevant for us and we introduce a way to account for the negative interpretation of $\mathrm{N}$-words in pre-verbal position; after that, we go back to our proposal in more detail. We first summarize some core notions of the ERP methodology and how it can be used to investigate the processing of sentences and linguistic mechanisms. Then we present our study and its results, and we discuss their implications for a linguistic and psycholinguistic account of mai.

\subsection{NPIs and exhaustification}

In this section, we briefly sketch Chierchia's theory of NPIs and in particular the analysis of any and ever. The main characteristics are the following: a) any and ever have the meaning of existential quantifiers (over some pragmatically determined domain of individuals or time intervals respectively); b) they are obligatorily 
exhaustified with respect to their domain alternatives, in a sense to be explained below; c) their distribution and interpretation is determined by the result of this exhaustification. A first question for this analysis regards the difference between NPIs like any and other existential quantifiers like $a$ or some (and analogously, the difference between ever and sometimes). In fact, sentences (20a) and (20b) appear to have the same truth conditions; so what is the difference between them? What is the contribution of any?
a. If you make a mistake, you will not pass.
b. If you make any mistakes, you will not pass.

Kadmon and Landman (1993) and Lahiri (1998) suggested that the interpretation of any in sentences such as (20b) involves widening the domain of individuals over which the existential quantifies, so that (20b) would take into account a wider quantificational domain than (20a). For example, it would consider types of mistakes that are generally not considered, such as spelling or stylistic mistakes. This can account for the intuition that when we construct a dialogue like (21) (adapted from Kadmon and Landman, 1993), (21c $=20 \mathrm{~b})$ seems to say something stronger than $(21 \mathrm{a}=20 \mathrm{a})$.

(21) a. A: If you make a mistake, you will not pass

b. B: Not if I make just a spelling mistake

c. A: I tell you that if you make any mistake, you will not pass 
A second more pressing question regards the more restricted distribution of NPIs like any (and ever), with respect to other existential quantifiers. In other words, why is (22a) grammatical and (22b) ungrammatical?
(22) a. John ate some broccoli.
b. *John ate any broccoli.

Chierchia (2011), building on Kadmon and Landman (1993), Krifka (1995), Lahiri (1998) and Chierchia (2004, 2006), proposes a formalization of the intuition about domain widening above that also accounts for the distribution of any and other NPIs. The components of the analysis are the following: first, both some and any have a regular and identical existential semantics, as in (23) (where D is a free variable over quantificational domains, see Westerståhl, 1985, and much subsequent work).

$$
\llbracket \text { some }=\llbracket \text { any } \rrbracket=\lambda P \lambda Q[\exists x \in \mathrm{D}[P(x) \wedge Q(x)]]
$$

The semantics in (23) simply says that, given two arguments of predicative type, there is an individual in some pragmatically selected domain D that satisfies both. Hence any has the same basic lexical entry as some. The difference lies in the fact that any obligatorily activates smaller domain alternatives. Domain alternatives are obtained by replacing the variable D with variables D' of the same type ranging over smaller non-empty domains. For instance, in the example in (22b), D could be all the broccoli in the house, while D' can 
be any subset of $\mathrm{D}$ : the broccoli in the fridge, the ones on the table, and so on. A formulation of the domain alternatives for an NPI like any is in (24).

$$
\mathrm{Alt}_{\mathrm{D}}(\mathbf{a n y})=\left\{\lambda P \lambda Q\left[\exists x \in \mathrm{D}^{\prime}[P(x) \wedge Q(x)]\right]: \mathrm{D}^{\prime} \subseteq \mathrm{D}\right\}
$$

We assume a multidimensional semantics along the lines of Rooth (1992) and Chierchia (2004, 2011), in which alternatives are introduced by certain lexical elements and grow with pointwise composition. More specifically, we assume that alternatives have the following characteristics:

(i) The alternatives of a lexical element $\alpha$ are either the singleton set containing $\{\alpha\}$ itself, if $\alpha$ does not belong to a scale, or the set $\left\{\alpha_{1} \ldots \alpha_{n}\right\}$ if $\alpha$ is part of a scale $<\alpha_{1} \ldots \alpha_{\mathrm{n}}>$.

(ii) The alternatives to $[\alpha \beta]$ is the set derived by applying each member in the set of alternatives to $\alpha$ to each member in the set of $\beta$ (pointwise functional application).

Given this assumptions about alternatives, (22b) winds up having the meaning in (25a) and the alternatives in (25b).
a. $\exists x \in \mathrm{D}[\operatorname{broccoli}(x) \wedge \operatorname{ate}(j, x)]$
b. $\left\{\exists x \in \mathrm{D}^{\prime}[\operatorname{broccoli}(x) \wedge \operatorname{ate}(j, x)]: \mathrm{D}^{\prime} \subseteq \mathrm{D}\right\}$ 
The way Chierchia (2011) formalizes the exhaustification of a sentence with respect to its alternatives is by assuming a covert operator EXH with a meaning akin to overt only (see also Fox, 2007, and Chierchia, Fox and Spector, 2012, among others). ${ }^{4}$ The meaning of EXH is given in (26): given a propositional argument and a set of alternatives, it returns the conjunction of that proposition and the negation of the alternatives that are not entailed by it.

$$
\operatorname{EXH}(\operatorname{Alt} D)(p)(w)=p(w) \wedge \forall \mathrm{q} \in \operatorname{Alt}_{\mathrm{D}}[(\mathrm{p} \nsubseteq \mathrm{q}) \rightarrow \neg \mathrm{q}(\mathrm{w})]
$$

Chierchia (2011) ensures that the alternatives of NPIs not only can but must be exhaustified by using a feature checking mechanism. The gist of the idea is the following: NPIs have a feature $[+\mathrm{D}]$, which indicates that their domain alternatives are active and requires agreement with the exhaustivity operator EXH, which then has to be obligatorily present, as indicated in (27).

$$
\left[*(\mathrm{EXH})\left[\text { any }_{+\mathrm{D}}\right]\right]
$$

How does this analysis account for the ungrammaticality of (22b)? We can now see that once we exhaustify (22b) with respect to its smaller domain alternatives, we get a logical contradiction. What (28) says is that there is at least one piece of broccoli in some domain D that John ate, but that for all non-empty subsets D' of D, there is no broccoli that John ate. This is clearly impossible, hence we end up with a meaning that can never 
be true.

$$
\begin{aligned}
& \mathrm{EXH}[(22 \mathrm{~b})]=\exists x \in \mathrm{D}[\operatorname{broccoli}(x) \wedge \operatorname{ate}(j, x)] \wedge \\
& \left.\neg \exists x \in \mathrm{D}^{\prime}[\operatorname{broccoli}(x) \wedge \operatorname{ate}(j, x)]\right] \text { for all non empty } \mathrm{D}^{\prime} \text { such that } \mathrm{D}^{\prime} \subseteq \mathrm{D}
\end{aligned}
$$

The hypothesis is that this contradictory meaning is the source of the ungrammaticality of (22b). ${ }^{5}$ The account of the distribution of NPIs lies in the fact that the exhaustification of (smaller) domain alternatives always gives rise to a contradiction in non-DE contexts, but not in DE ones. To illustrate this latter case, consider the meaning of (29a) in (29b) and its alternatives in (29c).
a. John didn't eat any broccoli
b. $\neg \exists x \in D[\operatorname{broccoli}(x) \wedge \operatorname{ate}(j, x)]$
c. $\left\{\neg \exists x \in D^{\prime}[\operatorname{broccoli}(x) \wedge \operatorname{ate}(j, x)]: D^{\prime} \subseteq D^{\prime}\right\}$

Notice that the domain alternatives are all entailed by (29b): if there is no broccoli in some domain D that John ate, there won't be any broccoli in all subdomains D' of D. Hence, given the way EXH is defined, it will turn out to be vacuous in this case. In other words, as indicated in (30), the meaning of (29a) is simply (29b) and it is obviously non-contradictory. The non-contradictoriness would explain the grammaticality of (29a) against the minimally different $(22 b)$. 
The analysis of ever proposed by Chierchia (2011) is exactly the same as that of any but the domain of quantification is a domain of time intervals instead of one constituted by individuals, so that (31a) is analyzed as (31b) with the alternatives in (31c): there is some time interval $t$ in a domain D such that there is an event of meeting Chomsky occurring at $t$, of which John is the agent.

a. $\quad$ *John ever met Chomsky.
b. $\quad \exists t \in D[\exists e[\operatorname{met}(e, j, c) \wedge$ at $(e, t]]$
c. $\quad\left\{\exists t \in D^{\prime}[\exists e[\operatorname{met}(e, j, c) \wedge\right.$ at $\left.(e, t)]]: D^{\prime} \subseteq D^{\prime}\right\}$

Accordingly, (32a) is analyzed as (32b) with the alternatives in (32c), hence, in the very same way as above, the exhaustification of (31b) gives rise to a contradiction and explains the ungrammaticality of (31a), whereas the exhaustification of (32b) is just vacuous.
a. John didn't ever meet Chomsky.
b. $\quad \neg \exists \mathrm{t} \in \mathrm{D}[\exists \mathrm{e}[\boldsymbol{m e t}(\mathrm{e}, \mathrm{j}, \mathrm{c}) \wedge \operatorname{at}(\mathrm{e}, \mathrm{t})]]$
c. $\quad\left\{\neg \exists \mathrm{t} \in \mathrm{D}^{\prime}[\exists \mathrm{e}[\boldsymbol{m e t}(\mathrm{e}, \mathrm{j}, \mathrm{c}) \wedge\right.$ at $\left.(\mathrm{e}, \mathrm{t})]]: \mathrm{D}^{\prime} \subseteq \mathrm{D}\right\}$ 

a. $\operatorname{EXH}[(31 \mathrm{a})]=$ contradiction
b. $\quad \operatorname{EXH}[(32 a)]=(32 a)$

Summing up, the interpretation of NPIs like any and ever is modeled using three ingredients: a) existential quantification over some pragmatically determined domain, b) the obligatory activation of smaller domain alternatives, and c) exhaustification of such alternatives. The consequence of these steps is that NPIs give rise to non-contradictory meanings only when they appear in DE environments. In the next section we extend this approach to analyze mai.

AN ANALYSIS OF MAI

2.1 $m a i$ as an NPI

We adopt Chierchia's analysis of ever above, so that (34a) has the meaning in (34b): there is no time interval in some domain D such that there is an event of Gianni being in Cuba occurring at $t$. The alternatives in (34c) are all entailed by (34b), hence, in the same way as above, the exhaustification of (34a) is simply vacuous (34d).

(34) a. Gianni non è mai stato a Cuba 


\title{
Gianni hasn't ever been to Cuba
}

$$
\begin{aligned}
& \text { b. } \quad \neg \exists \mathrm{t} \in \mathrm{D}[\exists \mathrm{e}[\mathbf{b e}-\mathbf{i n}(\mathrm{e}, \mathrm{g}, \mathrm{c}) \wedge \text { at }(\mathrm{e}, \mathrm{t})]] \\
& \text { c. } \quad\left\{\neg \exists \mathrm{t} \in \mathrm{D}^{\prime}[\exists \mathrm{e}[\mathbf{b e}-\mathbf{i n}(\mathrm{e}, \mathrm{g}, \mathrm{c}) \wedge \text { at }(\mathrm{e}, \mathrm{t})]]: \mathrm{D}^{\prime} \subseteq \mathrm{D}\right\} \\
& \text { d. } \quad \operatorname{EXH}[(34 \mathrm{a})]=(34 \mathrm{a})
\end{aligned}
$$

In non-DE contexts, instead, the domain alternatives are not entailed by the assertion and the application of EXH yields a contradictory outcome: there is a time interval in some domain D in which Gianni has been to Cuba, but there is no time in any subdomain D' of D such that Gianni has been to Cuba.
a. *Gianni è mai stato a Cuba
Gianni has ever been to Cuba
b. $\exists t \in \mathrm{D}[\exists e[\mathbf{b e}-\mathbf{i n}(e, g, c) \wedge \operatorname{at}(\mathrm{e}, \mathrm{t})]]$
c. $\left\{\exists t \in \mathrm{D}^{\prime}[\exists e[\mathbf{b e}-\mathbf{i n}(e, g, c) \wedge\right.$ at $\left.(\mathrm{e}, \mathrm{t})]]: \varnothing=\mathrm{D}^{\prime} \subseteq \mathrm{D}\right\}$
d. $\operatorname{EXH}[(35 \mathrm{a})]=\exists t \in \mathrm{D}[\exists e[\mathbf{b e}-\mathbf{i n}(e, g, c) \wedge$ at $(\mathrm{e}, \mathrm{t})]] \wedge$
$\neg \exists t \in \mathrm{D}^{\prime}[\exists e[\mathbf{b e}-\mathrm{in}(e, g, c) \wedge$ at $(\mathrm{e}, \mathrm{t})]]$ for all non-empty $\mathrm{D}^{\prime} \subseteq \mathrm{D}$

\begin{abstract}
So far the behavior of mai closely mirrors that of existential NPIs like any. What we need to add at this point is an account of the negative interpretation in non-DE contexts in pre-verbal position. We turn to this in the next section.
\end{abstract}




\subsection{Accounting for the negative interpretation in pre-verbal position}

Building on Laka (1990), Ladusaw (1992), and Alonso-Ovalle and Guerzoni (2004) propose that (Italian and Spanish) $\mathrm{N}$-words in pre-verbal positions are interpreted negatively, through the presence of an abstract negation in the syntax. Contrary to Ladusaw and Laka, who suggest that the abstract negation is in the same position as overt negation, Alonso-Ovalle and Guerzoni propose that the position of covert negation is higher in the structure. Following Rizzi (1997), they assume that there is some position within the extended complementizer phrase projection (CP), which focalized constituents move to, and they claim that N-words, which appear pre-verbally, have moved to this position. They also claim that the head of this projection, generally called FocP, can host a silent negative feature ([neg]), which is responsible for the negative interpretation of $\mathrm{N}$ words (after they have reconstructed below it at LF). ${ }^{6}$

$$
\left[\text { FocP } \operatorname{Nessuno}\left[\varnothing_{[n e g]}\left[{ }_{\mathrm{IP}} t_{1}\right]\right]\right]
$$

We remain neutral on how to analyze N-words, but we argue for a similar analysis for mai in pre-verbal position. Recall that the conditions under which mai can be interpreted negatively are that mai must occur in a pre-verbal position and it must not be in a DE context. We account for this generalization in the following way: mai always has an existential meaning and in pre-verbal position always moves to FocP. The difference 
with Alonso-Ovalle and Guerzoni (2004) concerns the assumption that the movement of mai to FocP always occurs when mai appears in pre-verbal position. If mai is not in a DE environment then it has to reconstruct at LF and in FocP a negative feature has to be present. On the other hand, when mai is in a DE environment, it can be interpreted in FocP and no negative feature is inserted. Notice that if the possibility of inserting a negative feature in FocP is created by the movement of mai to its specifier, under the assumption that a projection is not present if nothing moves to it, we can also account for why the insertion of covert negation cannot happen when mai appears in post-verbal position. We are now ready to put this together with the theory above: in DE contexts, mai is interpreted as ever regardless of its syntactic position. Exhaustification is vacuous in such a case, because the assertion entails all the alternatives. If, on the other hand, mai occurs in a pre-verbal position but not in a DE environment, mai has to reconstruct in the scope of an abstract negation that is added to the structure.

Mai avrei pensato che a Gianni piacessero i broccoli I would never have thought that Gianni likes broccoli

$$
\left[_{\text {FocP }} \text { Mai }\left[\varnothing_{[n e g]}\left[\text { IP } \text { pro avrei } t_{1} \text { pensato }\right]\right]\right]
$$

Summing up, we propose that mai has an existential NPI-like semantics. If mai occurs in a DE context, exhaustification yields a logically consistent result. If mai occurs in a non-DE context in pre-verbal position an abstract negation is added into the structure 
and exhaustification of the alternatives can be successfully performed. Otherwise, if mai appears post-verbally negation cannot be inserted and the sentence results in ungrammaticality as the exhaustification yields a contradiction.

For the purposes of this paper, we do not defend this analysis over its competitors on theoretical grounds. Instead, we show that it allows us to formulate experimental hypotheses about specific mechanisms that are involved in the interpretation of mai (i.e. exhaustification and covert negation) in interaction with the alternatives it activates, and how they are processed on-line. More specifically, we aim to explore by means of ERP methodology how the processor makes use of the information associated with these mechanisms.

\section{FROM THEORY TO PROCESSING}

In the previous sections we outlined some linguistic facts about the behavior of mai in relation to the different linguistic environments in which it occurs. Then we proposed a theory that accounts for this behavior. The main ingredients of the proposal are: a) an alternative-based analysis of mai as an NPI and b) a mechanism for adding a covert negation to the sentence, under certain conditions. In this section we discuss how our theoretical proposal is linked to on-line processing and the predictions that we make as to how mai is processed in the brain. These predictions are tested in the experiment that we present in the subsequent section. Before going to our experiment, we briefly 
introduce some key notions about ERPs and how they have been used to investigate linguistic phenomena. This will help to highlight and clarify the motivations underlying the choice of the ERP technique for our investigation.

\subsection{ERPs in psycholinguistics}

ERPs are variations in the electricity recorded on the scalp (via electroencephalogram) in response to a given event - a word in our case. ERPs present a very high temporal resolution and have shown a strong sensitivity to several linguistic contrasts. For this reason they have been intensely employed in psycholinguistic investigation during the last forty years. ERP experiments are conducted by visual presentation of the stimuli (i.e. on a computer screen, one word at a time) or by auditory presentation. The evoked signal is recorded by several electrodes, which occupy different positions on the scalp. The ERP methodology allows us to make inferences as to how the cognitive system reacts to external stimulation. In particular we can tell whether two conditions are processed differently in the brain by comparing the mean amplitude of the signal they evoke in response to the critical event and how this signal is distributed on the scalp (topography). For example, if condition A is more positive (or negative) in a subset of electrodes than

condition $\mathrm{B}$, it suggests that the contrast between A and B involves underlying cognitive processes that reveal themselves in such positivity (or negativity). Moreover, if two or more contrasts (e.g. A vs. B and A vs. C) elicit differential waves (i.e. A - B and A - C) with a different distribution in time and space, we can infer that such contrasts involve 
different underlying cognitive processes.

In psycholinguistic research, certain brain waves have been found to correlate with certain linguistic phenomena. Such waves, called ERP components, can be identified from their latency (the time elapsing between the onset of the critical word and the effect) and their topography (which electrodes show the effect). If our experimental manipulation affects one of these components we may infer that it involves the cognitive processes that are thought to underlie such components.

One type of contrast that has often been employed in ERP studies is obtained through the use of linguistic violations. In psycholinguistics, a violation is a sentence that sounds deviant. Its deviancy may be due to different reasons: it can be pragmatically odd or structurally ungrammatical. Syntactic violations, for instance, are sentences violating syntactic rules, and they have been extensively studied. One example of this kind of violation is obtained through the mismatch in the agreement of the number feature exemplified in (39a), and was investigated in the work of Kaan and Swab (2003).
a. $\quad *$ The child throw the toy.
b. The children throw the toy.

The authors found that the critical word throw in (39a) generates a positivity after $600 \mathrm{~ms}$ in the posterior electrodes, as compared to its presentation in (39b). This effect, called P600 wave, has been found in several experiments in association with other kinds of syntactic violations and ungrammatical sentences (cf. Osterhout and Holcomb, 1992; 
Hagoort, Brown and Groothusen, 1993). For this reason the P600 is argued to index the effort to detect or repair an illicit phrasal structure, originated by the violation of a syntactic rule. Another kind of deviancy that has been repeatedly investigated is the socalled conceptual or knowledge violation. In their study, Kutas and Hylliard (1980) presented speakers of English with sentences like those in (40a) and (40b).

(40) a. She spread the warm bread with socks.
b. She spread the warm bread with butter.

The authors found that the odd continuation in (40a) elicited a negativity at the word socks that reached its peak around $400 \mathrm{~ms}$ on central electrodes. This negativity has been called N400, and it has been further replicated by several other studies (cf. Kutas, Van Petten and Kluender, 2006 for an overview). It is interpreted as the struggle of the brain to cope with awkward meaning and unpredictable continuations that are hard to integrate with the interpretation of the sentence.

An assumption shared by ERP studies employing deviant sentences is that our brain elicits different waves in response to different types of violation. As a consequence, different mental processes are argued to come into play in detecting or attempting to resolve different types of conflicts. One appealing interpretation regarding the difference between P600 and N400 processing streams is that they would mirror the division between the domains of rule-based linguistic vs. non-linguistic conceptual knowledge (cf. Choudhary, Schlesewsky, Roehm and Bornkessel-Schlesewsky, 2009 and Panizza, 2012, 
for discussion). The P600 processing stream would be sensitive to the former domain, and affected by syntactic violations. The N400 processing stream would be sensitive to the latter domain, and affected by conceptual violations. There is, however, experimental evidence going against this subdivision coming precisely from ERP studies on NPI violations, which reported N400 (Saddy, Drenhaus and Frisch, 2004; Pablos, Shirley, Erdocia, Laka, Williams and Saddy, 2011) or both N400 and P600 (Drenhaus, Błaszczak and Schütte, 2007; Steinhauer, Drury, Portner, Walenski and Ullman, 2010) in association with unlicensed NPIs. One way to characterize NPI violations is to define them as violations of logic-based formal rules that are specific to language, which cause semantic clashes. In a sense, unlicensed NPIs violate both formal syntactic and semantic constraints. In the next section we make explicit the link between our analysis of sentences with mai and their processing on-line.

\subsection{Linking theory and processing}

In this section we describe the structure of the four experimental conditions employed in this study, and outline their linguistic configuration with respect to the position of the critical word mai in the structure. The first two conditions employ mai in post-verbal position. In one condition, it is licensed by negation, (41a), while in the other negation is absent (41b). This contrast allows us to investigate the processing effects associated with the unlicensed occurrence of mai. In the third condition, (41c), mai appears in pre-verbal position. Comparison with the conditions in which it occurs post-verbally can inform us 
about how the processor deals with this particular use of mai, associated with a negative interpretation. To complete our experimental design we added a fourth condition (41d) where mai occurs pre-verbally in an ungrammatical sentence, so that our experimental design is composed of two grammatical vs. two ungrammatical sentences and two preverbal vs. two post-verbal occurrences of mai. In the next paragraphs we illustrate each condition and the contrasts it gives rise to.
a. Gianni non ha mai incontrato Chomsky
Gianni hasn't ever met Chomsky
b. *Gianni ha mai incontrato Chomsky
Gianni has ever met Chomsky
c. Gianni mai ha incontrato Chomsky
Gianni has never met Chomsky
d. Gianni non mai ha incontrato Chomsky
Gianni hasn't ever met Chomsky

Let's go back to the comparison of a sentence like (41a) and (41b): in both cases mai occurs in post-verbal position, but only in (41a) is it in a DE context. In fact, the two sentences are identical with the only difference being the presence of negation in (41a). According to the analysis outlined in the preceding sections, (41a) and (41b) have the LF in (42a) and (42b), respectively. 


$$
\begin{aligned}
& \text { a. } \left.\left.\left.\quad \text { EXH [Gianni [ non [ ha mai }{ }_{[+D]} \text { incontrato Chomsky }\right]\right]\right] \\
& \text { b. EXH [Gianni ha mai }[++\mathrm{D}] \text { incontrato Chomsky }]
\end{aligned}
$$

As shown above, the meaning we obtain for (42a) is a coherent one: there is no time interval (in some domain D) such that there is an event of Gianni meeting Chomsky at that time interval. On the other hand for $(42 b)$ we obtain a contradiction: there is at least a time interval (in some domain D) such that there is an event of Gianni meeting Chomsky at that time but there is no such time in all the subsets D' of D. As mentioned above, we assume, following Chierchia (2011), that the reason underlying the ungrammaticality of (41b) is the contradiction deriving from exhaustification of the sentence with respect to its alternatives. We expect a contrast like the one between (41a) and (41b) to generate processing differences, as found with NPI violations in other languages. If so, by the assumptions of our model, together with the idea that the processor is immediately sensitive to this contrast (i.e. as soon as mai is encountered), we are led to draw the conclusion in (43).

(43) The ERP effects generated from the comparison between a case like (41a) and (41b) are a consequence of the semantic clash generated by (41b). These effects are either directly caused by the contradictory meaning yielded by the output of exhaustification or are induced by the reaction of the processor to this conflict. This reaction involves the detection of the conflict and the strategies that come into play in the attempt to resolve it. 
The hypothesis in (43) just says that the formal operation that we claim is at the basis of the violation in (41b) causes processing effects; ${ }^{7}$ any effect generated by this contrast is assumed to underlie this operation and it will serve as a guide to investigate the other contrasts.

The third condition investigates the processing of mai occurring in pre-verbal position in a grammatical sentence, as exemplified in (41c), repeated below.

(41c) Gianni mai ha incontrato Chomsky

Gianni has never met Chomsky

As discussed in the previous sections, a sentence like (41c) has a negative interpretation (mai is interpreted as never). In our analysis, we account for this by postulating that a covert negation is added to the structure. Critically, however, we do not know in advance when this operation is performed in on-line processing: is it performed immediately upon encountering mai in pre-verbal position or is it done after an interpretation without such covert negation is attempted? Our model is compatible with both hypotheses that, in turn, lead to two different predictions. We spell out the first hypothesis in detail in (44).

(44) Hypothesis 1 (predicting monotonicity): Upon encountering mai in a sentence like (41c) the processor can access immediately the information that mai is not embedded in a DE context and that no verbs have occurred yet (using syntactic and 
semantic cues). As a consequence, a covert negation is added in before the sentence is exhaustified.

The prediction for the processing of (41c) is that ERP effects generated by the comparison between (41c) and (41a) should affect different components as compared to the ones generated by (41b) vs. (41a), as in (41c) exhaustification winds up yielding a consistent output. Thus, any processing effect elicited by the word mai in (41c), as compared to the baseline case in (41a), may be traced back to the additional operations that are associated with its occurrence in pre-verbal position (focalization and the insertion of a covert negation in the structure). In other words, according to (44) the pre-verbal occurrence of mai is not predicted to elicit any ERP that is correlated with the failure of exhaustification.

Our theory is also compatible with a second hypothesis that we spell out in (45).

(45) Hypothesis 2 (covert negation as a reanalysis): During on-line processing, the information that mai must be interpreted negatively is not immediately available. Instead, this information must be recovered in some way. Hence, upon encountering mai the processor does not yet know whether mai is in a DE context or not. Exhaustification is thus performed and it generates a logical contradiction. This information triggers the operation of adding a covert negation to the structure.

According to this hypothesis, the insertion of covert negation is conceived of as a 
reanalysis that happens after an attempt to interpret the structure without covert negation. The predictions of (45) are that the ERP effects generated by the comparison between (41c) and (41a) should again be caused by a logical contradiction, which is yielded by the first attempt of exhaustification before covert negation is added. Hence, these two contrast effects should affect the same components, for they underlie the same cognitive operations.

The last condition of our experimental design is illustrated in (41d), repeated below. The sentence in (41d) is ungrammatical, but it differs from the other ungrammatical condition in (41b) in that mai occurs in pre-verbal position and in the fact that it contains an overt negation. ${ }^{8}$

*Gianni non mai ha incontrato Chomsky Gianni hasn't ever met Chomsky

We argue that (41d) gives rise to a violation that is very different in nature from that of (41b). Whereas in (41b) the logical clash is argued to be the primary cause of its ungrammaticality, the cause of the deviancy of (41d) is a violation of a purely syntactic constraint: there is no licit structure in which non and mai can appear in this configuration. One account of this which is in line with our analysis is the following: when mai appears in pre-verbal position, this means that it has moved to a high position in the structure (FocP); in that position there is no higher place that could host an overt negation that could then appear before mai in linear order. This analysis is compatible 
with several outcomes as to the comparison between (41d) and the other conditions. First of all, the reason underlying the deviancy of (41d) is different from that explaining the ungrammaticality of (41b), hence we might predict those conditions to be processed differently by the brain. For instance the presence of the overt negation in (41d) could prevent the construction of any syntactic structure, and thus block the interpretation of mai. Alternatively, the processor could somehow apply the negation to mai anyway, ignoring the fact that it constructed an illicit structure. Another possible outcome is that the processor ignores (at least temporarily) the negative marker and interprets mai as if no negation had occurred. This last possibility implies that mai is exhaustified in a non-DE context and thus generates the same effects as its unlicensed occurrence in (41b). We acknowledge that the investigation of (41d) is exploratory in nature, and we leave the interpretation of the effects revealed by this condition to the discussion section below.

Summing up, we discussed some hypotheses about linking our theory to processing, which revolve around the following three questions: a) how does our brain react to an unlicensed occurrence of mai? b) how does it deal with a mai in pre-verbal position? c) do different sources of ungrammaticality have an effect on how mai is processed on-line? We turn now to our study, which focuses on these questions.

\section{THE EXPERIMENT}

In the following, we summarize the design, methods and results of the experiment. See 
Panizza, Vespignani, Zandomeneghi and Job (under review), for a full description of the experimental methods and complete statistical analysis.

\subsection{Design and methods}

The experimental design that we employed is composed of four conditions as exemplified in (46a)-(46d). The variables manipulated in the conditions are: a) the position of mai (pre- or post-verbal) and b) the presence/absence of negation.

(46) a. post-verbal, negation, grammatical

Mario pensa che Gianni non abbia mai incontrato Chomsky. Mario thinks that Gianni hasn't ever met Chomsky.

b. post-verbal, no negation, ungrammatical

* Mario pensa che Gianni abbia mai incontrato Chomsky. Mario thinks that Gianni has ever met Chomsky.

c. pre-verbal, no negation, grammatical

Mario pensa che Gianni mai abbia incontrato Chomsky. Mario thinks that Gianni has never met Chomsky.

d. pre-verbal, negation, ungrammatical

*Mario pensa che Gianni non mai abbia incontrato Chomsky. Mario thinks that Gianni hasn't ever met Chomsky. 
Notice that (46a)-(46d) are just the sentences discussed in the section above, apart from the fact that the critical word (mai) is embedded in a subordinate clause to prevent readers from assigning the sentence an interrogative interpretation. In fact, as an interrogative, the embedded clause of (46b) is grammatical (it is interpreted as has Gianni ever met Chomsky?). As mentioned above, the ungrammaticality of (46b) could be accounted for by assuming that FocP is projected only if something moves to it. In this case, post-verbal mai does not move to FocP, thus there is no place for inserting covert negation in the structure and, hence, we predict that (46b) cannot be rescued in the same way as (46c).

The experimental manipulation is constituted of the combination of two factors with two levels each. The first factor is the position of mai with respect to the verb (preverbal in (46c) and (46d) vs. post-verbal in (46a) and (46b)); the second factor is the grammaticality of the sentence (grammatical in (46a) and (46c) vs. ungrammatical in (46b) and (46d)). This last factor was obtained by manipulating the presence of an overt negation (non) in the sentence: in the post-verbal conditions an overt negation licenses mai (46a), whereas its absence renders the sentence ungrammatical (46b). In the preverbal conditions, on the other hand, mai is grammatical when negation is absent (46c), whereas it is ungrammatical when a negative marker occurs before it (46d).

A group of 24 Italian monolingual speakers were presented with a set of 160 experimental sentences divided into the four conditions reported above. Sentences appeared on a computer screen, each word was presented alone for $300 \mathrm{~ms}$ and followed 
by a blank screen for $300 \mathrm{~ms}$, and participants had to judge the sentence acceptability (acceptability judgment) by pressing a keyboard button right after they completed the reading. Experimental items were interspersed with fillers, which were grammatical or ungrammatical, taken from other studies. ERPs were time-locked to the onset of each word. The focus of our interest is ERPs elicited by the critical word mai.

\subsection{Results}

The participants accepted the grammatical sentences like (46a) and (46c) and rejected the ungrammatical ones like (46b) and (46d) in the majority of trials as expected. ${ }^{9}$ The results show that both ungrammatical conditions in (46b) and (46d), compared to the baseline condition in (46a), elicited a centrally distributed negativity between 250 and $400 \mathrm{~ms}$ from the onset of mai. Its onset and topography is comparable to that of an N400. This effect was followed by a frontal positivity detected at $500 \mathrm{~ms}$ (Frontal P600, FP600) and by a posterior positivity that was elicited from $600 \mathrm{~ms}$ up to 1 second, which can be classified as a P600. The grammatical condition containing a pre-verbal occurrence of mai (46c), compared to (46a), generated an even higher N400 effect followed by an FP600 with the same onset and amplitude as the one elicited by the ungrammatical conditions. However, no P600 effect was revealed by this last comparison. These results are summarized in the table below. 


\begin{tabular}{|l|l|l|l|l|l|}
\hline sentence & position of $m a i$ & grammaticality & N400 & FP600 & P600 \\
\hline$(46 a)$ & postverbal & grammatical & - & - & - \\
\hline$(46 b)$ & postverbal & ungrammatical & yes & yes & yes \\
\hline$(46 c)$ & pre-verbal & grammatical & yes & yes & no \\
\hline$(46 d)$ & pre-verbal & ungrammatical & yes & yes & yes \\
\hline
\end{tabular}

Table 1. Overall comparison of the ERP effects elicited by mai

\subsection{Discussion}

Two clusters of ERP effects emerge from the data. One is constituted by a negative wave (N400) followed by a frontal positivity (FP600); it is elicited by mai in the two ungrammatical conditions $((46 \mathrm{~b})$ and $(46 \mathrm{~d}))$ and by the grammatical pre-verbal occurrence of mai in (46c). The other one is a late positivity with posterior distribution (P600) and it is elicited by mai in the ungrammatical conditions only ((46b) and (46d)).

First of all, we interpret the result that the grammatical pre-verbal occurrence of mai (46c) elicited the pattern N400 and FP600 in the same way as the ungrammatical condition in (46b), supporting Hypothesis 2 (covert negation as a reanalysis) above. This suggests that upon encountering mai the processor does not yet know that it should introduce a covert negation and attempts a first interpretation without it, thereby generating a contradiction. This hypothesis conceives of the insertion of a covert negation as a result of a reanalysis that occurs when a first interpretation gives rise to a contradiction (and mai occurs in a pre-verbal position). As a consequence of this, our 
results do not support the idea that the information that is required to predict the negative interpretation of mai in pre-verbal position (i.e. DE-ness) is already accessed at the point at which mai is processed, contrary to Hypothesis $\mathbf{1}$ (predicting monotonicity).

Secondly, the two illicit occurrences of mai in pre- and post-verbal position $((46 b)$ and $(46 d))$ generated a similar ERP profile; in particular they both generated an N400 followed by a FP600 and by a P600. Once again, the cluster composed by N400 + FP600 was also found in the grammatical pre-verbal condition (46c). If it is right that the cause of this pattern can be attributed to the contradiction resulting from exhaustification and the following attempt to perform a semantically triggered reanalysis of the sentence, we conclude that in the ungrammatical condition this contradiction also has to arise. In these conditions, however, the N400+FP600 effects were also followed by a P600, which is likely to index the detection of illicitness and the effort to repair it. This explains why in (46c) no P600 was revealed.

Furthermore, this supports the idea that at the moment at which the reader hits mai in (46d), its interpretation is not blocked, but rather is performed ignoring, at least temporarily, the negation that cannot find a place in the structure. As a consequence, mai is exhaustified in a non-DE context and this process results in a logical contradiction exactly like in the condition in which there was no licensor at all (46b).

Going back to how mai is processed in pre-verbal position, our interpretation raises a general question about how the linguistic system is designed; that is, why can't the processor access immediately (i.e. prior to interpretation) the information indicating that a negation is to be added? One possible answer, inspired by Reinhart (2006), is that 
we are dealing with an imperfection of the system at the syntax/semantics interface. In a perfect system, the syntactic rules would provide an unambiguous and univocal input to the semantic interpretative operations. The case of pre-verbal mai can be conceived of as an exception to this regularity. Namely, it is an example of a case where the processor, in order to figure out how to construct the right structure, is required to perform some semantic computations (i.e. the exhaustification of mai). Along these lines, the reanalysis that is constituted by the insertion of a negation in the structure, can be thought of as a repair strategy performed by the processor to cope with this imperfection of the system.

Summing up, the dissociation that we found between the clusters of effects formed by N400 + FP600 on the one hand, and the P600 on the other, supports the model sketched in the diagram in Fig. 1, which assumes an existential semantics for mai and the involvement of certain formal operations (exhaustification of alternatives, insertion of negation).

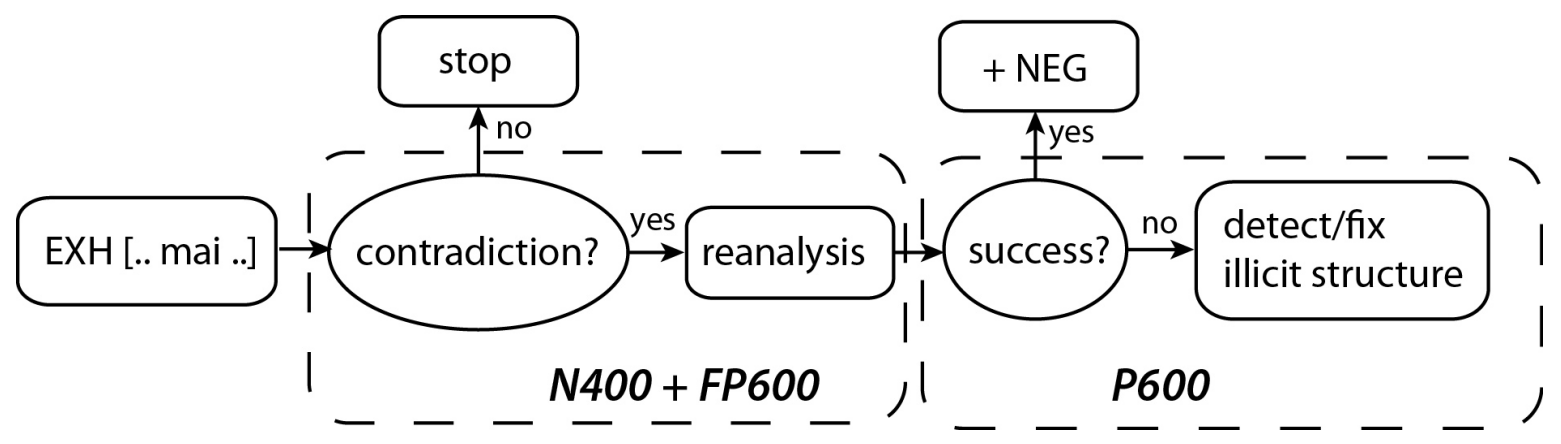

Figure 1. The stages of the on-line processing of mai

During on-line processing, all sentences with mai, regardless of its position, are interpreted with obligatory exhaustification. If the result is not contradictory mai retains 
its non-negative interpretation. If it is contradictory, a reanalysis of the sentence is attempted. Thus, if mai occurs in pre-verbal position (i.e. it has moved to FocP) the reanalysis with insertion of covert negation can be performed and the final outcome of this process is the negative interpretation of mai in (46c). If the reanalysis does not succeed, as in the ungrammatical conditions ((46b) and (46d)), the final outcome is the detection and repair of an illicit structure, which is revealed in a P600 effect as often found in the ERP literature (see references in section 3.1 above and 4.4 below).

One might wonder whether the mere availability of an NPI licensor or the position of mai in the structure can each by themselves explain the results we presented. For example, if we only compare the two grammatical conditions (46a) and (46c), such alternative explanations might work, as the differential ERP pattern elicited by mai in these conditions might be traced back to the effect of these two factors. As a matter of fact, the lack of a processing difference between the two ungrammatical conditions (46b) and (46d), which differ from each other in both the presence of negation and the position of mai, is clear evidence against an account that only relies on these considerations.

Another objection that could be raised against the way we interpreted the results is the following: recall that the grammatical pre-verbal occurrence of mai elicited $\mathrm{N} 400+$ FP600 effects, just like the ungrammatical conditions, as compared to the control. One alternative interpretation of these data is that the pre-verbal mai does not involve a contradictory exhaustification, and these effects would be due to the mechanisms of focalization and negation insertion, as immediately performed by the processor. In other words, different cognitive operations would reflect themselves in the same ERP 
components, namely N400 and FP600. We acknowledge that this hypothesis cannot be ruled out a priori, as we can infer that different ERP effects are at the basis of different cognitive processes but not that different cognitive processes must be associated with different ERP effects. However, we believe that our explanation is to be preferred over this alternative one as it offers a better match between cognitive processes and psychophysiological effects, and, moreover, it is supported by other findings coming from ERP studies on NPIs and syntactic violations in which N400 and FP600 effects were reported, as we discuss in the next paragraphs.

\subsection{A brief comparison with other ERP studies}

In this section, we discuss the results of our experiment in relation to the current ERP literature on NPI violations and other psycholinguistic studies (again, see Panizza et $a l$, under review, for an extensive review of the ERP literature). First of all, two of the sentence types we employed were ungrammatical at the onset of the critical word mai. Unsurprisingly, we found a late posterior positivity (P600) in these conditions, as also found by the majority of studies employing ungrammatical sentences as well as NPI violations. In the psycholinguistic literature, posterior positivities (P600) are argued to underlie processes of detection and repair of illicit phrase structures (see references in section 3.1 above). Our results are in line with this interpretation, in that they show a selectivity of the P600 for the grammatical status of the sentence. 
The other main result of our study is the N400 + FP600 pattern elicited by mai in the two ungrammatical conditions and when it occurs in pre-verbal position in a grammatical sentence. Several experimental works also report an N400 effect elicited by unlicensed NPIs in different languages. This list includes jemals in German (Drenhaus et al., 2006; Saddy et al., 2004; Drenhaus et al., 2007), at all (Steinhauer et al., 2011), and ezer in Basque (Pablos et al., 2011). Recall that N400 effects are often reported in association with words that lead to odd and unusual meanings, and the fact that NPI violations affect this component is surprising. Drenhaus et al. attempt to trace a parallelism between NPI violations and violations of contextual knowledge, claiming that what they have in common is that they are both hard to integrate with the context. Steinhauer et al., on the other hand, defend the idea that these N400 effects are not related to interpretive issues. They claim that NPI violations do generate logical clashes that, however, would affect the P600 component, like other anomalies due to the violation of linguistic rules (see also Xiang, Dillon and Phillips, 2009). Our interpretation, in line with Drenhaus et al., is that N400 effects were caused by semantic problems at the logical level. However, such problems are due to the violation of rules that are indeed linguistic in nature, which end up affecting the N400 component (as well as the FP600 in our study). We believe this interpretation is attractive for two reasons. First, it accounts for the fact that NPI violations elicited N400s in several studies (see section 3.1 above). ${ }^{10}$ Second, it finds further support in recent studies on other types of ungrammatical sentences that, although involving violations of syntactic rules, still engender dramatic problems for the interpretation of the sentence. In such studies, as in ours, N400 effects were often found in association with 
P600 ones. Examples of these studies are those employing thematic violations of casemarking and thematic roles (Choudhary et al., 2009; Frisch and Schlesewsky, 2001) and person agreement mismatch (Mancini, Molinaro, Rizzi and Carreiras, 2011).

Finally, a few words on the FP600 effect we reported: this component is far less common than the N400 and P600, and it is often referred to as broadly distributed P600 if found in association with a posterior P600 (cf. Friederici, Hahne and Saddy, 2002). It has been associated with discourse complexity by Kaan and Swaab (2003) and by Dwivedi, Phillips, Lague-Beauvais and Baum (2006). Dwivedi et al. in particular interpreted this effect as a correlate of the reanalysis of the discourse/sentence structure. We will not go into further details, but we just note that this last interpretation is compatible with the one we proposed, that is, a reanalysis of the first structure that was initially computed.

\section{CONCLUSIONS}

In this paper we focused on the on-line processing of alternatives and exhaustification by looking at the case of mai, which exhibits the properties of both NPIs and N-words. We first advanced a theoretical proposal: an alternative-based analysis of mai as an existential NPI which can license the insertion of a covert negation when in pre-verbal position and in a non-DE context. Then we discussed various hypotheses about how this theory can be linked to on-line processing and we investigated these hypotheses through an ERP experiment. The main results are: 
(1) covert negation is a result of a reanalysis of the sentence after its interpretation has led to a contradiction;

(2) this reanalysis was also attempted when facing illicit occurrences of mai, due to different reasons; in such cases it was not sufficient to restore the interpretation of the sentence.

To conclude, mai, and NPIs in general, is one classic case in which abstract properties of sentences, such as entailment patterns, have a deep impact on their meaning and distribution. In the present work we elaborated on the theoretical links between these logical properties, semantic alternatives and the operations that are performed on these alternatives (e.g. exhaustification), and we tested the hypothesis we advanced as to the use that the processor makes of such operations. As it turns out, entailment patterns and semantic alternatives play an important role in on-line processing of polarity sensitive items such as mai. Alternatives and entailment patterns have already been shown to affect other phenomena such as the computation of scalar implicatures (Panizza, Chierchia and Clifton, 2009). We leave for future research the investigation of parallels and differences in the processing of these linguistic phenomena.

\section{Acknowledgments}

Authors' names appear in alphabetical order. We are grateful to Gennaro Chierchia and Francesco Vespignani, who inspired the idea of this work more than five years ago, 
between Cambridge (MA) and Rovereto (Italy). We also want to thank many people for their comments and insightful suggestions: Paolo Zandomeneghi (who devoted his master thesis to this experiment), Hazel Pearson (for a thorough review and bright suggestions), Simona Mancini, Lyn Frazier, Chuck Clifton and the UMass psycholinguistics group, Massimiliano Guidetti (for the 'Cuba example'), three anonymous reviewers and the editor of this book.

\section{Endnotes}

1. An occurrence of mai in post-verbal position is in (i). Notice that when an auxiliary is present, mai can follow the auxiliary and precede the verb, as in (iia). Its occurrence after the verb is still possible, as shown in (iib). We refer to the positions of mai in (i), (iia) and (iib) as "post-verbal".

(i) Gianni non viene mai

Gianni doesn't come ever

(ii) a. Non ho mai mangiato i broccoli 
b. Non ho mangiato mai i broccoli

2. Downward entailing environments are created in the scope of downward entailing operators, which are functions that reverse the entailment patterns of their arguments. For instance, smoking entails smoking cigars (generalizing entailment to predicative types, see Chierchia, 2011, for discussion) but every student who smokes will come entails every student who smokes cigars will come. More formally, a function $f$ is downward entailing iff for any arguments $a, b$, such that $a$ entails $b$, then $f(b)$ entails $f(a)$.

3. Zanuttini (1991) observes that in a restricted set of cases (e.g. a subset of DE contexts and indirect questions) in which Italian N-words in preverbal position appear to acquire a non-negative interpretation. These cases are exemplified in (i) and (ii).

(i) Dubito che nessuno venga.

I doubt that anybody will come.

(ii) Mi domando se nessuno è venuto.

I wonder whether anybody came.

We and other native speakers we consulted are only able to read (i) and (ii) assigning to nessuno a negative interpretation, namely as "I doubt that no-one will come" and "I wonder whether no-one came", respectively. At any rate, even if (i) and (ii) could be read by some speakers with a non-negative interpretation, what is critical for our purposes is that, unlike 
mai, N-words like nessuno systematically acquire a negative reading in all DE contexts and questions when they occur in pre-verbal position, not just a in some restricted cases.

In connection with this, it is also worth mentioning that mai, to our knowledge, is the only word that exhibit this special behavior. In Spanish, the counterpart of mai is nunca, and it behaves like a typical N-word in every respect: it has a non-negative meaning and it always requires a negation if it occurs post-verbally (iii, iv), whereas it is interpreted negatively if it occurs pre-verbally, even if it is embedded in questions and DE contexts (iv, v).

(iii) (no)* he tomado nunca una cerveza.

I have (not)* ever drunk a beer.

(iv) (no)* has tomado nunca una cerveza?

have (not)* you ever drunk a beer?

(iv) nunca has tomado una cerveza?

have you never drunk a beer?

(v) si nunca has tomado una cerveza, no puedes saber si te gusta o no.

If you have never drunk a beer, you cannot know whether you like it or not.

4. The operator EXH can also be used to give a theory of scalar implicatures and in fact one motivation of Chierchia's account is giving a unified analysis of NPIs and scalar 
implicatures. However, as he discusses, one could adopt the exhaustivity-based theory just for the analysis of NPIs. For our purposes, we can remain neutral on this issue.

5. See Gajewski (2002) and Hackl and Fox (2007) for discussion of the difference between this type of contradiction, which leads to ungrammaticality, and other seemingly contradictory sentences which instead give rise to grammatical sentences such as (i).

(i) This square is not a square

6. More precisely, they assume that the abstract feature [neg] requires an overt specifier with matching morphology. N-words have negative morphology that can satisfy this requirement. N-words in sentence-initial position move to Spec-FocP to license the abstract negation.

7. Notice that we are not making any prediction as to which effects should be elicited by the contrast in (42a) vs. (42b). Discussing this sort of prediction would require a deep analysis of the effects reported by the other studies as well as of the cognitive models that are assumed, and this falls outside the scope of the present work. Here we only mentioned the N400 and P600 effects, which are good candidates for such predictions, but NPI violations also elicited other ERP waves (see Steinhauer et al., 2010). We leave a brief comparison with the ERP literature for the last section. 
8. A question at this point is what happens if we have a preverbal occurrence of mai followed by overt negation, like in (i).

Context: Il nuovo direttore non ha lasciato la mancia.

The new director didn't leave the tip.

(i) Il vecchio direttore MAI non ha lasciato la mancia.

The old director never didn't leave the tip.

The sentence is marginally acceptable, as in English, with stress on mai and a double negation interpretation (the old director always tipped).

9. Notice that the acceptance rate for sentences in the pre-verbal grammatical condition (46c) was smaller than that for the other conditions $(70 \%$ vs. $80-90 \%)$. This difference was due to a small number of participants (4/24) that did not consistently accept the condition in (46c). This may be a consequence of the fact that the pre-verbal use of mai in Italian is marked and relatively infrequent. Moreover, mai has to be stressed by a phonological contour (i.e. under focus) when occurring in that position. During the word-by-word reading this operation might have been difficult to perform for those participants who ended up judging it unacceptable.

10. One result coming from our study is the N400 and FP600 that we found associated 
with mai occurring in pre-verbal position in a grammatical sentence. Drenhaus et al. (2007) report a similar finding: they found an N400 effect when jemals is under the scope of the interrogative pronoun welcher (i) as compared to the same sentence with negation.

(i) Welcher Jäger hat den Angler jemals gestört?

Which hunter has ever disturbed the fisherman?

While the issue of how NPIs are licensed in questions is a controversial one, one might try to account for this finding using strategy akin to the one we pursued to account for our data. Namely, if we assume that the semantics of questions permits NPI licensing in the same way as DE contexts do (i.e. by allowing a non-contradictory exhaustification of the alternatives introduced by the NPI), the readers might have not assigned to (i) the interrogative status prior to encountering the NPI jemals, which would have been interpreted in a non licensing context and generated a contradictory meaning resulting in the N400 effect. 


\section{References}

L. Alonso-Ovalle and E. Guerzoni (2004) 'Double Negation, Negative Concord and Metalinguistic Negation' in M. Andronis, E. Debenport, A. Pycha and K. Yoshimura (eds.) Proceedings of the Chichago Linguistics Society Meeting: The Main Session. (Chicago:

CLS Publications), pp. 15-31.

G. Chierchia (2004) 'Scalar implicatures, polarity phenomena, and the syntax/pragmatics interface' in A. Belletti (ed.) Structures and beyond (Oxford: Oxford University Press).

G. Chierchia (2006) 'Broaden your Views: Implicatures of Domain Widening and the “Logicality” of Language', Linguistic Inquiry, 37(4), 535-590.

G. Chierchia (2011) Recursive pragmatics, Ms. Harvard University.

G. Chierchia, D. Fox and B. Spector (2012) 'The Grammatical View of Scalar Implicatures and the Relationship between Semantics and Pragmatics' in C. Maienborn, K. von Heusinger and P. Portner (eds.) Semantics. An international handbook of natural language meaning; Volume 1 (Berlin and New York: Mouton de Gruyter).

K. Choudhary, M. Schlesewsky, D. Roehm and I. Bornkessel-Schlesewsky (2009) 'The 
N400 as a correlate of interpretively-relevant linguistic rules: Evidence from Hindi', Neuropsychologia, 47, 3012-3022.

H. Drenhaus, P. Graben, D. Saddy and S. Frisch (2006) 'Diagnosis and repair of negative polarity constructions in the light of symbolic resonance analysis', Brain and Language, $96,255-268$.

H. Drenhaus, J. Blaszczak and J. Schütte (2007) 'Some psycholinguistic comments on NPI licensing' in E. Puig-Waldmüller (ed.) Proceedings of Sinn und Bedeutung 11 (Barcelona: Universitat Pompeu Fabra), pp. 180-193.

V. Dwivedi, N. A. Phillips, M. Lague-Beauvais and S. Baum (2006) 'An electrophysiological investigation of mood, modal context and anaphora', Brain Research, $1117,135-153$.

D. Fox and M. Hackl (2006) 'The Universal Density of Measurement', Linguistics and Philosophy, 29(5), 537-586.

D. Fox (2007) 'Free choice and the theory of scalar implicatures' in U. Sauer- land and P. Stateva(eds.) Presupposition and Implicature in Compositional Semantics, Palgrave, pp. $71-120$. 
S. Frisch and M. Schlesewsky (2001) 'The N400 indicates problems of thematic hierarchizing', Neuroreport, 12, 3391-3394.

A. D. Friederici, A. Hahne and D. Saddy (2002) 'Distinct Neurophysiological Patterns Reflecting Aspects of Syntactic Complexity and Syntactic Repair', Journal of Psycholinguistic Research, 31, 45-63.

J. Gajewski (2002) 'L-Analiticity and Natural Language', Ms. University of Connecticut.

P. Hagoort, C. Brown and J. Groothusen (1993) 'The syntactic positive shift as an ERPmeasure of syntactic processing', Language and Cognitive Processes, 8, 439-483.

C. Hamblin (1973) 'Questions in Montague grammar', Foundations of Language, 10(1), $41-53$.

A. Hahne and A. D. Friederici (1999) 'Electrophysiological evidence for two steps in syntactic analysis: Early automatic and late controlled processes', Journal of Cognitive Neuroscience, 11, 194-205.

E. Kaan and T. Y. Swaab (2003) 'Repair, Revision, and Complexity in Syntactic Analysis: An Electrophysiological Differentiation', Journal of Cognitive Neuroscience, 15(1), 98110. 
N. Kadmon and F. Landman (1993) 'Any', Linguistics and Philosophy, 15, 353-422.

M. Krifka (1995) 'The Semantics and Pragmatics of Polarity Items', Linguistic Analysis, $25,209-257$.

M. Kutas and S. A. Hillyard (1980) 'Reading senseless sentences: Brain potentials reflect semantic incongruity', Science, 207, 203-205.

M. Kutas, C. Van Petten and R. Kluender (2006) 'Psycholinguistics electrified II: 19942005' in M. Traxler and M. A. Gernsbacher (eds.) Handbook of psycholinguistics, 2nd edn. (New York: Elsevier).

W. A. Ladusaw (1979) Polarity Sensitivity as Inherent Scope Relations, PhD dissertation (University of Texas: Austin).

W. A. Ladusaw (1992) 'Expressing negation' in C. Barker and D. Dowty (eds.), Proceedings of the SALT 2 (Columbus: OSU), pp. 237-259.

U. Lahiri (1998) 'Focus and negative polarity in Hindi', Natural Language Semantics, $6(1), 57-123$. 
I. Laka (1990) Negation in Syntax: on the Nature of Functional Categories and Projections, PhD dissertation (Cambridge: MIT).

S. Mancini, N. Molinaro, L. Rizzi and M. Carreiras (2011) 'When persons disagree: an ERP study of Unagreement in Spanish', Psychophysiology, 48, 1361-1371.

L. Osterhout and P. J. Holcomb (1992) 'Event-related brain potentials elicited by syntactic anomaly', Journal of Memory and Language, 31, 785-804.

L. Pablos, E. Shirley, K. Erdozia, I. Laka, N. Williams and D. Saddy (2011) 'Licensing of Negative Polarity Items in Basque: an ERP study' Poster presented at the 10th International Symposium of Psycholinguistics, BCBL.

D. Panizza (2012) 'Formal Neurosemantics. Logic, Meaning and Composition in the Brain', Journal of Neurolinguistics, 25(5), 460-488.

D. Panizza, F. Vespignani, P. Zandomeneghi and R. Job (under review) 'Never in the wrong place: An ERP study on N-words in Italian'.

T. Reinhart (2006) Interface Strategies. Optimal and Costly Computations (Cambridge: MIT Press). 
L. Rizzi (1997) 'The fine structure of the left periphery' in L. Haegeman (ed.) Elements of grammar (Dordrecht: Kluwer Academic Publishers), pp. 281-337.

M. Rooth (1992) 'A theory of focus interpretation', Natural Language Semantics, 1,75117.

D. Saddy, H. Drenhaus and S. Frisch (2004) 'Processing polarity items: Contrastive licensing costs', Brain and Language, 90, 495-502.

K. Steinhauer, J. E. Drury, P. Portner, M. Walenski and M. T. Ullman (2010) 'Syntax, concepts, and logic in the temporal dynamics of language comprehension: Evidence from event-related potentials', Neuropsychologia, 48, 1525-1542.

D. Westerståhl (1985) 'Determiners and context sets'. in J. van Benthem and A. ter Meulen (eds.) Generalized Quantifiers in Natural Language (Dordrecht: Foris), 45 - 71.

M. Xiang, B. W. Dillon and C. Phillips (2009) 'Illusory Licensing Effects across Dependency Types: ERP evidence', Brain and Language, 108, 40-55. 
